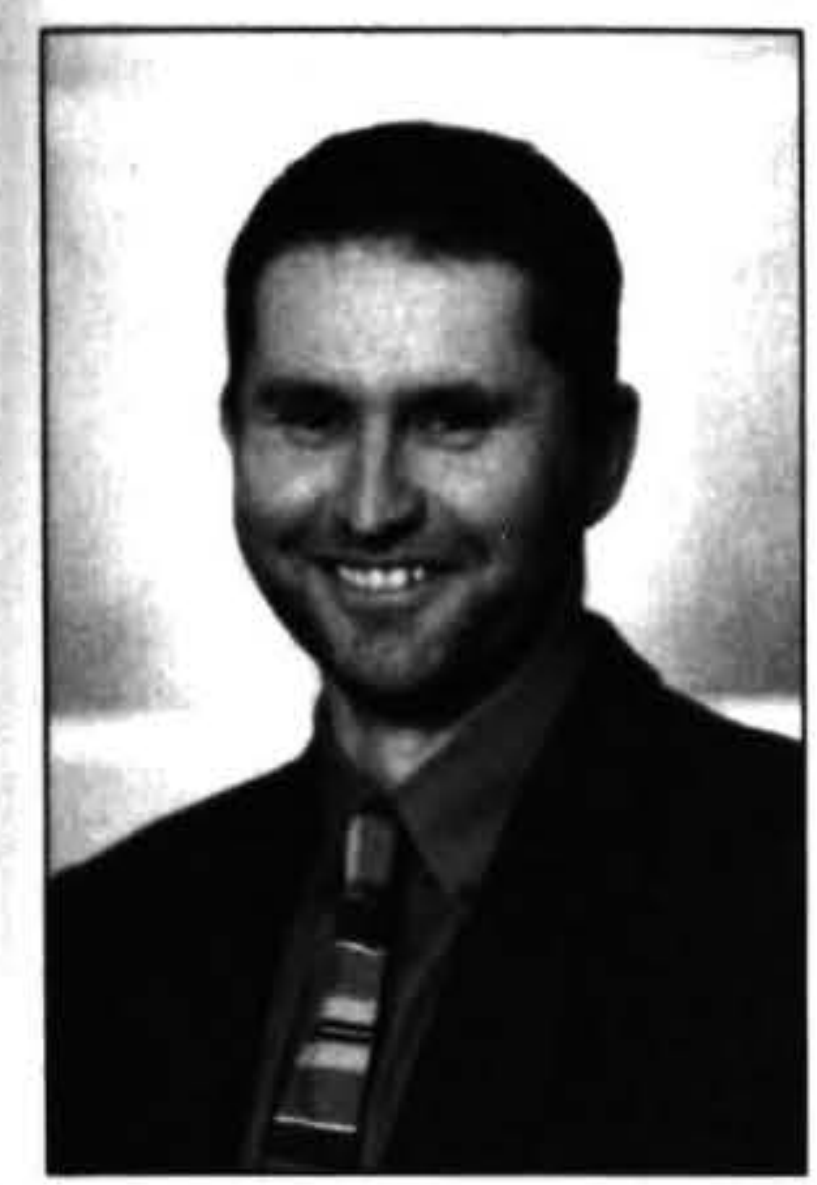

\title{
SKILL SHORTAGES IN THE TRADES: A REPORT CARD
}

\author{
Andrew Whiteford \\ Work Directions \\ Department of Labour, Wellington
}

\begin{abstract}
Shortages in the trades are acute and widespread. In 2005 the Department of Labour published an overview of skill shortages in the trade occupations and identified the major reasons for those shortages. This paper revisits some of the historical causes of shortages in the trades. While the legacy of these factors is still being felt in today's labour market. there have been significant improvements in most areas. Qualification achievements and enrolments have been lifted significantly, migration is making a net positive contribution to supply, and wages have risen sharply. These developments are contributing to growth in supply of tradespersons, which coupled with the expected slowing of growth in demand, means the outlook for shortages is much improved.
\end{abstract}

\section{Introduction}

A defining feature of the New Zealand labour market over the past six years has been the rapid growth in demand for labour and skills. This has resulted in a sharp fall in unemployment to levels that are low by New Zealand historical as well as international standards. The fall in unemployment has been accompanied by record high skill and labour shortages which have constrained the economy and inhibited the provision of health, community and other services.

The shortage of trades workers has been particularly acute. In 2004 the Department of Labour (the Department) estimated that only $41 \%$ of advertised trade vacancies were filled within ten weeks of advertising ${ }^{2}$. The Department identified the major reasons for these shortages. These included the low number of people entering the trades in the 1990s, low training levels in the early 2000s, net migratory outflows in late and early 2000 s, the lack of attractiveness of some of these occupations and the construction boom. This current paper will revisit these issues and discuss progress in addressing the shortage of trade workers. Particular attention is paid to the level of training and a view on an appropriate level of future trade training is presented. The final section offers an outlook for shortages in the trades.

The paper draws on results from the Department of Labour's Job Vacancy Monitoring Programme (JVMP). The JVMP was established early in 2003 to identify which skilled occupations are in shortage, and to better understand the supply and demand forces contributing to these shortages. It comprises a number of components including surveys of employers, analysis of advertised vacancies and in depth investigations into occupations in shortage. Further details on the JVMP can be obtained from http://www.dol.govt.nz/publications/jvm/job-ad -infosheet.asp

\section{Overall Picture}

The shortage of trades workers was widespread and acute in 2005. The Department's Survey of Employers who have Recently Advertised (SERA) measured that just over a third $(37 \%)$ of the 1,480 vacancies included in the survey sample were filled within ten weeks of advertising. 'Line Mechanic' had the lowest fill rate $(10 \%)$, while 'Printing Machinist' had the highest $(61 \%)$. Of the 14 trades surveyed, nine had fill rates less than $40 \%$ and are therefore considered to be in acute shortage. Six of the trades surveyed had fill rates less than $30 \%$. This indicates the depth of shortage within the trades surveyed.

All 14 trades surveyed were assessed as experiencing 'genuine skill shortages'. Genuine skill shortages occur when employers have difficulties filling their job vacancies because there are not enough individuals with the required skills in the potential labour market to fill the positions on offer.

The overall fill rate for all trades surveyed in $2005(37 \%)$ was lower than that measured in $2003(48 \%)$ ) signifying a deepening of shortages over this period. While the fill rates for a few trade occupations improved between 2003 and 2005 (for example, the fill rate for Bricklayer rose from $32 \%$ to $42 \%$ ) most fill rates dropped over this period. For some occupations, this drop was substantial (for example, the fill rate for Diesel Mechanic fell from $48 \%$ to $21 \%$ ). 


\section{Revisiting the Identified Reasons for Trade Shortages}

This section revisits the original reasons identified by the Department of Labour in their report titled 16 Trade Occupation Shortage Reports: An Overview. This report summarised the findings from in-depth investigations into 16 trade occupations which were based on analysis of trends up to 2004. The recent progress made in addressing these reasons for the shortage of trade workers is reported on in the current paper. It draws on the follow up report titled Skill Shortages in the Trades: The 2005 Picture. The latter report provides an overview of findings from in-depth investigations into 14 trade occupations.

\section{Reason One: The Number of Young People Entering the Trades Dropped Sharply in the 1990s}

The sharp drop in the number of young people entering the trades is clearly illustrated by the changing age profile of trade workers measured in the 1991, 1996 and 2001 population censuses. For instance, the number of fitters and turners between the age of 20 and 24 declined from nearly 1.150 in 1991 to slightly more than 200 in 2001

Employers interviewed in the SERA indicated that changes to the apprenticeship system in the 1990s impacted negatively on training. Other factors mentioned by employers included the downscaling of many government department-based apprentice training initiatives, economic recession, and the rising proportion of young people embarking on tertiary academic study in New Zealand

Figure 1: Total enrolment in trade qualification, 20012005.

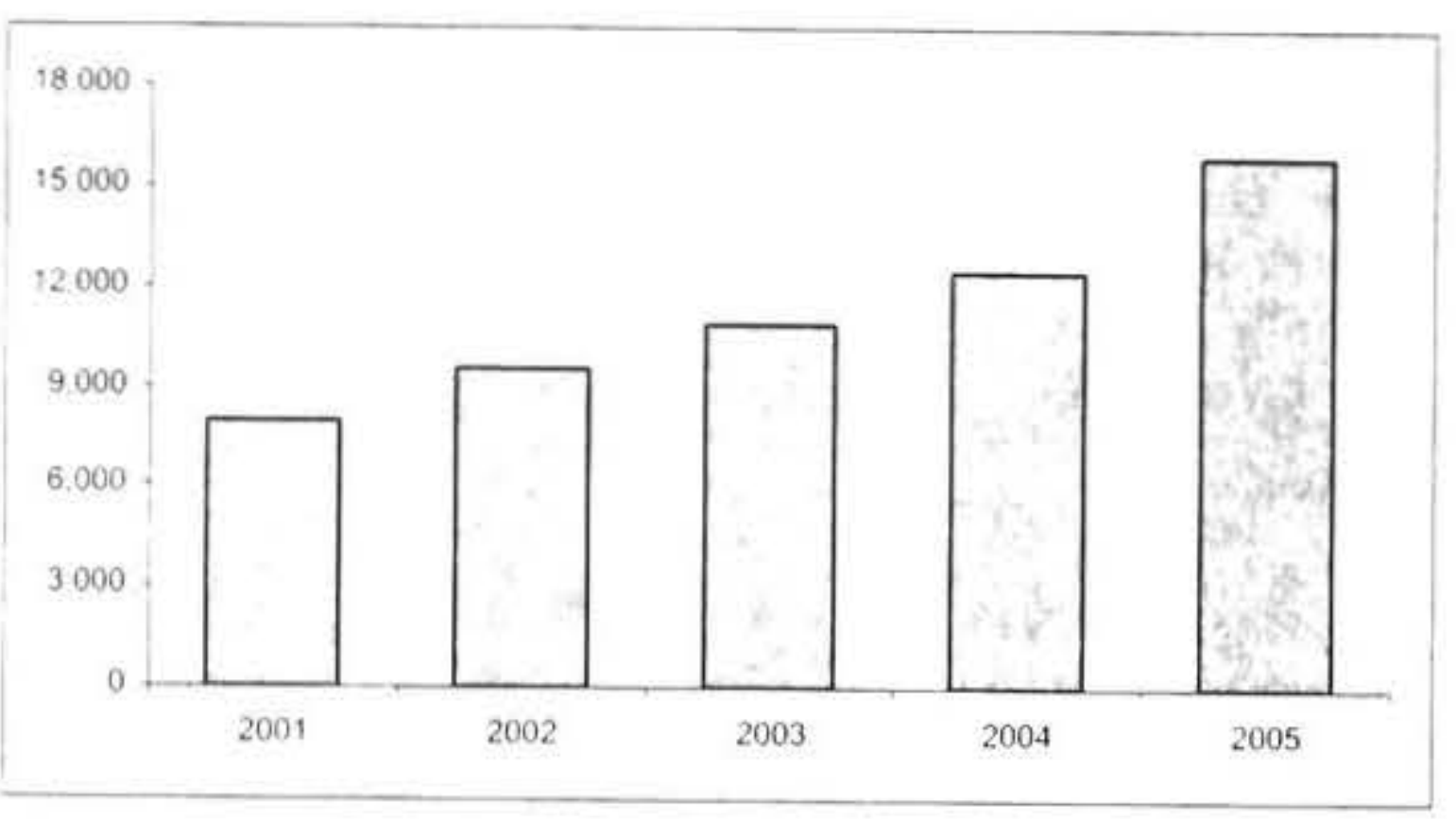

Source: Department of Labour estimates based on data from industry training organisations and Tertiary Education Commission.

The decline in young people entering the trades has reversed sharply. The total number of trainees enrolled for qualifications related to the 14 trade occupations under review doubled from slightly less than 8.000 in 2001 to almost 16.000 in 2005 (see Figure 1). The carpenter occupation was the largest contributor to this growth, with enrolments increasing more than three-fold, from about 2.360 to 7,900 . All occupations showed an increase over the five year period, and all except one (fitter and turner) experienced growth in excess of $10 \%$.
Reason Two: Training Rates at National Certificate Level 4 Have Been Low for Much of the 2000s

In the early years of the current decade the level of training (expressed as the training rate) was considerably lower than the growth in demand for trade occupations. The trade training rate measures the number of people achieving the benchmark National Certificate Level 4 qualification as a percentage of the number of people employed in trades. It is a measure of the annual growth in the supply of trades through training, and is conceptually comparable with the growth in demand (as measured by growth in employment). For instance, in 2003 the trade training rate for the 14 trade occupations analysed in the current trade reports was $2.3 \%$. While that level of training was adequate to compensate for retirements (which occur at the rate of about $1.3 \%$ per annum), it was insufficient to cope with new demand (job creation) which occurred at the rate of about $3.0 \%$ per annum. The 2003 trade training rate was lower than the New South Wales ${ }^{+}$, Australia trade training rate $(2.8 \%)$, where widespread shortages in the trades are also reported.

While low training rates have been identified as one of the historical contributors to trade shortages, the rate has been rising each year since the beginning of this decade. The trade training rate has risen from $2.0 \%$ in 2001 to $3.3 \%$ in 2005 (see Figure 2). The most impressive increase was for line mechanic - increasing from $0.5 \%$ to $9.6 \%$ over the five year period. Boat builders also showed an impressive increase from $2.0 \%$ to $6.8 \%$. All occupations except printing machinist experienced a training rate increase.

Figure 2: Trade training rates, 2001-2005.

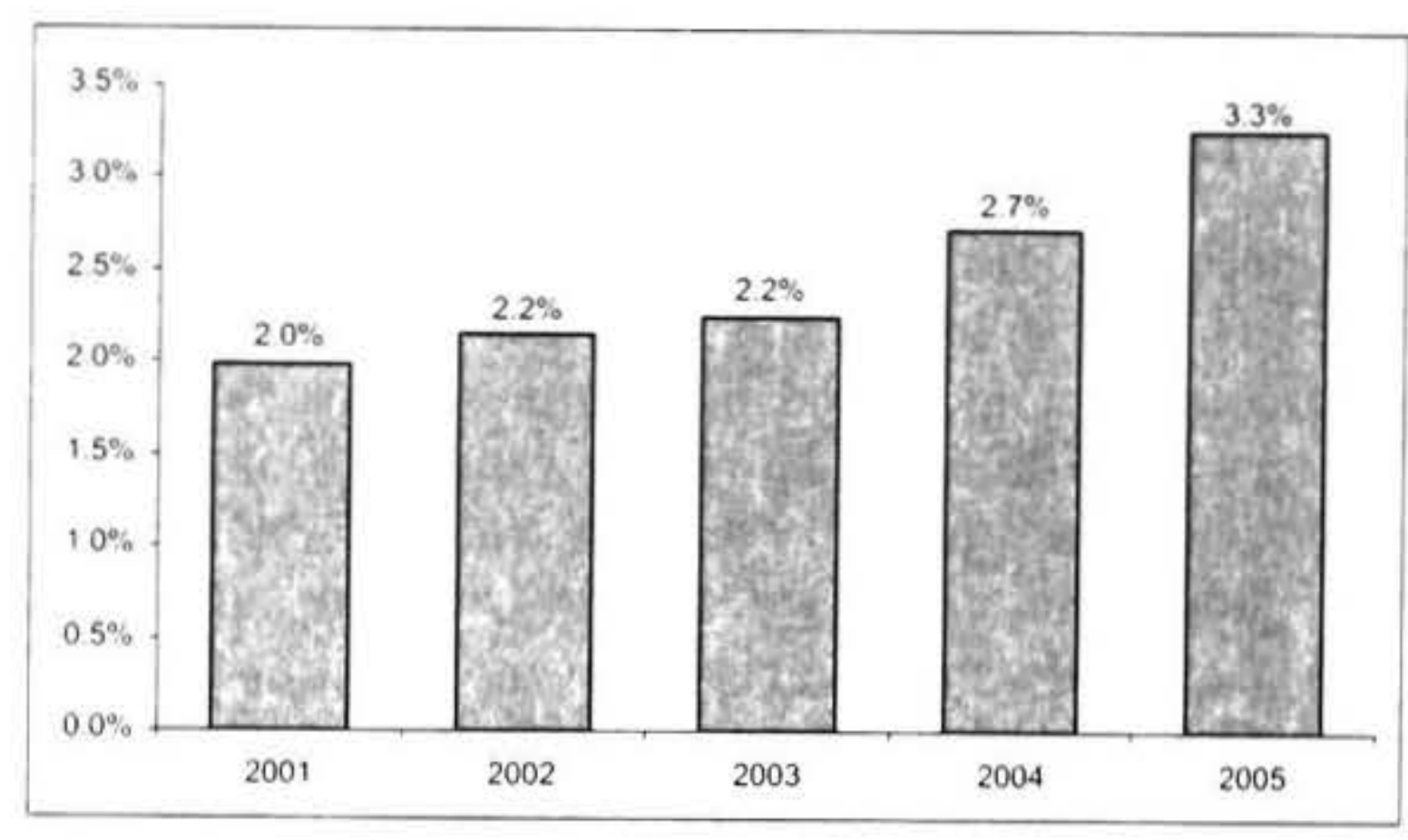

Source: Department of Labour estimates based on data from industry training organisations and Tertiary Education Commission.

The trade training rate of $3.3 \%$ in New Zealand in 2005 somewhat exceeds the training rate in New South Wales. Australia $(2.6 \%)$.

The strong growth in participation in industry training so far this decade has been well documented, but this finding that the trade training rate has risen sharply shows that increased participation is translating into greater numbers of qualification achievement at a high level. 
If the training rate of $3.3 \%$ measured in 2005 were to be sustained in 2006 it will probably be adequate to cope with retirements ( $1.3 \%$ per annum), new demand from employment creation (which is likely to slow given the slowing of economic growth), as well as make some impact on existing shortages. However, it is less clear that this level of training would be adequate in the long term as long term employment creation in the trades will exceed that expected in 2006. The Department's analysis suggests that a training rate of at least $4.0 \%$ is necessary in the long term.

The upward trajectory in the training rate therefore needs to be maintained for coming years. This may be possible given the increase in the number of people in the training pipeline coupled with higher budgeted expenditure for both Industry Training and Modern Apprenticeships. Funding for training through the Industry Training Fund will rise from \$118.3 million (all figures GST exclusive) in 2005/06 to $\$ 141.7$ million in 2006/07 (further increases are baselined and by 2009/10 funding will have reached $\$ 156.4$ million). Funding for Modern Apprenticeships is also increasing, with $\$ 30.7$ million in $2005 / 06$ rising to $\$ 37.9$ million in $2006 / 07$ and $\$ 48.7$ million in $2009 / 10$ and outyears.

\section{Reason Three: Migratory Outflows}

In the five years to 2001, the New Zealand economy experienced a net loss of more than 4,600 tradespersons. This significant loss occurred prior to and in the early years of a rapid economic expansion. The flows have improved in recent years. A positive net inflow of trades workers was recorded in each year from 2003 to 2005. However, the recent net inflows have been insufficient to compensate for the large net outflows between 1998 and 2001 .

Adjustments to immigration policy settings have contributed to the improved flow of trades workers into New Zealand. The addition of many trade occupations to the Long Term Skill Shortage List, and increased emphasis on employability in the selection of applicants for residency through the Skilled Migrant Programme, have made it easier for trades workers to obtain permanent residence in New Zealand. This is reflected in the growing proportion of trades workers who are approved for residence under the General Skills Category and its successor the Skilled Migrant Category. In 2002/03, $7 \%$ of principal applicants approved for residence in New Zealand through the General Skills Category were trades workers, while in 2004/05, 15\% of principal applicants approved through the Skilled Migrant Category were trades workers.

\section{Reason Four: Construction Boom}

While the general economic expansion since 1999 could be identified as a contributor to shortages in the trades the construction sector has been singled out due to its huge impact on the demand for trades. The booming construction industry (the value of work put in place has grown by $42 \%$ in the four years to December 2005) has resulted in rapid growth in demand for construction trades workers. While half of trades workers are employed in the construction trades the impact has been felt far beyond the construction industry. For example, higher wages offered in construction has attracted trades workers with transferable skills (e.g. boat builders and cabinetmakers) from other industries.

Growth in the construction sector has eased since the peaks of 2004 and 2005 although it is still growing strongly. The growth in the number of hours worked in the September 2006 quarter declined to $4.2 \%$ (compared to the same quarter in the previous year) from $9.2 \%$ and $14.7 \%$ in September 2005 and 2004, respectively.

\section{Reason Five: Lack of Attractiveness of Some Occupations}

Surveyed employers mentioned that trade occupations were out of vogue, discouraging young people from entering them. Pay rates and working conditions in some trades also discouraged people from choosing the occupation or caused them to leave.

The Department has identified a number of trade occupations - including chefs, cabinetmakers and hairdressers - as experiencing 'recruitment and retention difficulties". This occurs when there is a considerable supply of individuals with the required skills in the potential labour market but they are unwilling to take up or remain in employment at current levels of remuneration and conditions of employment.

Low relative wages were identified as contributors to recruitment and retention difficulties. The average wage rates of chefs (\$14.62 per hour) and cabinetmakers $(\$ 16.40)$ were $26 \%$ and $17 \%$ lower than the average wage rate for all trade occupations $(\$ 19.81)$, respectively. Working conditions also contributed to recruitment and retention difficulties. Employers of chefs spoke of long, unsociable hours and the stressful kitchen environment, while employers of cabinetmakers mentioned dirty working conditions as an issue.

The industry training organisations have put considerable effort into improving the image of the trades. The success of this is reflected in the increased enrolments in trade qualifications, outlined earlier in this paper.

The trades have enjoyed strong wage growth over recent years. The surveyed trades ${ }^{5}$ experienced an average growth in wages of $5.6 \%$ between June 2004 and June $2005^{6}$. This considerably exceeds the increase in the cost of living of $2.8 \%{ }^{7}$ over the same period, and the growth in wages across all occupations $(4.4 \%)$. Some trades showed exceptionally high wage growth; these include plumber $(9.4 \%)$, boat builder $(9.2 \%)$, cabinetmaker $(8.0 \%)$ and sheet-metal worker $(7.8 \%)$.

The rapid growth in wages in these occupations indicates that employers are responding to skill shortages by raising wages. Only two of the trades, bricklayer ${ }^{8}$ and chef, did not experience growth in wages in excess of the cost of living. That chefs experienced growth in wages below the growth in the cost of living is of concern as they are one of the occupations which were identified as 
displaying recruitment and retention difficulties. A decline in real wages suggests that this problem is worsening.

\section{Outlook}

Changes in both demand and supply conditions have markedly improved the outlook for shortages of trades workers. The demand for trades workers is expected to slow due to the overall slowing of the economy. According to the September 2006 consensus forecasts compiled by the New Zealand Institute of Economic Research, growth in gross domestic product is expected to slow to $1.5 \%$ in the year to March 2007 compared with $2.2 \%$ in the previous twelve months. Employment growth is expected to slow from $2.6 \%$ to $0.9 \%$ over the same time period. The slowdown in demand for trades workers is expected to be even more pronounced as the construction sector is likely to continue slowing in 2006.

While demand growth is easing, supply conditions will continue to improve. It has already been noted that training levels have grown strongly over the past few years and this trend will probably be maintained given the rise in enrolments for the Level 4 qualifications and the projected rise in expenditure on industry training. The Department expects net migration to increase slightly in 2007 due to a forecast rise in arrivals, supported by high levels of residency and work permit approvals. This should result in another year with a net positive inflow of trades workers.

For most trade occupations surveyed, the increase in supply will not be sufficient to eliminate current shortfalls. So while shortages are expected to ease, they will remain severe in the short-term. As training levels increase, the long-term outlook for trade occupations will improve.

\section{Conclusion}

This paper has revisited some of the historical causes of shortages in the trades. While the legacy of these factors is still being felt in today's labour market, there have been significant improvements in most areas. Qualification achievements and enrolments have been lifted significantly, migration is making a net positive contribution to supply, and wages have risen sharply. These developments are contributing to growth in supply of tradespersons, which coupled with the expected slowing of growth in demand, means the outlook for shortages is much improved.

\section{Notes}

1 Disclaimer: The Department of Labour has made every effort to ensure that the information contained in this report is reliable, but makes no guarantec of its accuracy or completeness and does not accept any liability for any errors. The information and opinions contained in this report are not intended to be used as a basis for commercial decisions and the Department accepts no liability for any decisions made in reliance on them. The Department may change, add to, delete from, or otherwise amend the contents of this report at any time without notice. The material contained in this report is subject to Crown copyright protection unless otherwise indicated. The Crown copyright protected material may be reproduced free of charge in any format or media without requiring specific permission. This is subject to the material being reproduced accurately and not being used in a derogatory manner or in a misleading context. Where the material is being published or issued to others, the source and copyright status should be acknowledged. The permission to reproduce Crown copyright protected material does not extend to any material in this report that is identified as being the copyright of a third party. Authorisation to reproduce such material should be obtained from the copyright holders.

Department of Labour, 2005. 16 Trade Occupation Shortage Reports: An Overview. http://www.dol.govt.nz/PDFs/trade-report -overview.pdf

These totals exclude enrolments through the relevant industry training organisation for the line mechanic and plumbing qualifications.

The New South Wales rate is the average training rate for the three years to June 2003.

No wage data is available for automotive electrician.

As measured by the unadjusted Labour Cost Index (LCI). The unadjusted index takes into account changes in pay related to the performance of individual employees.

As measured by growth in the Consumer Price Index.

The LCI measures wages of employees, and as a considerable proportion of bricklayers are self employed, a decline in the bricklayer wage rate does not imply a decline in earnings across the whole occupation.

\section{Author}

Andrew Whiteford

Senior Information Analyst

Labour Market Dynamics

Work Directions

Department of Labour

P.O. Box 3705

Wellington

Andrew.Whiteford@dol.govt.nz 